\title{
A VAR Approach to Exchange Rate and Economic Growth in Nigeria
}

\author{
Ukwuoma Chidi Okonkwo¹, Rosary N. Ujumadu², Bright O. Osu ${ }^{3}$ \\ ${ }^{1}$ Dept. of Mathematics/Statistics, Caritas University, Amorji-Nike Enugu, Nigeria \\ ${ }^{2}$ Dept. of Mathematics, Chukwuemeka Odumegwu Ojukwu University, Uli, Nigeria \\ ${ }^{3}$ Dept. of Mathematics, Michael Okpara University of Agriculture, Umudike, Nigeria \\ Email:Chukwuoma99@yahoo.com,rozyngujumadu@yahoo.com,megaobrait@hotmail.com
}

How to cite this paper: Okoronkwo, U.C., Ujumadu, R.N. and Osu, B.O. (2017) A VAR Approach to Exchange Rate and Economic Growth in Nigeria. Journal of $\mathrm{Ma}$ thematical Finance, 7, 834-845. https://doi.org/10.4236/jmf.2017.74044

Received: February 27, 2017

Accepted: October 28, 2017

Published: October 31, 2017

Copyright ( $) 2017$ by authors and Scientific Research Publishing Inc. This work is licensed under the Creative Commons Attribution International License (CC BY 4.0).

http://creativecommons.org/licenses/by/4.0/

(c) (i) Open Access

\begin{abstract}
Exchange rate is very pivotal in its role in the economy of any nation especially as a result of globalization. This paper seeks to model the Nigerian economy proxied by the log of Gross Domestic Product (LGDP) and its relationship with other variables in the economy. The variables used are NGN/USD exchange rate (NAIRA), log of oil revenue (LOILREV), log of government expenditure. We estimated the model using the Vector Autoregressive (VAR) model. We tested the presence or otherwise of causality among the variables using the method of Granger. The result reveals that the optimal lag for the model was 1 . The exchange rate was found to Granger cause the economy (LGDP), LOILREV (Oil Revenue) and LGEXP (Government expenditure). We also discovered that the dynamics of NAIRA was not fully captured by the variables used. We also pointed out the shock persistence of NAIRA in time.
\end{abstract}

\section{Keywords}

Exchange Rate, Vector Autoregressive (VAR) Model, Granger Causality

\section{Introduction}

Exchange rate is the price at which one country's currency is exchanged for that of another country. The exchange rate can be considered as the most important relative price in the financial world [1]. Exchange rate is significant because it helps to ensure exchange of goods and services among different countries, it determines the level of imports and exports and also helps to set domestic prices as well as maintain a balance in the economy.

Exchange rate volatility can be observed at any time in the day, week, month 
or year. The status of a country's economic well being is reflected by the real exchange rate. When the domestic income of a country increases, then the country' currency is likely to depreciate. However, an increase in foreign income would likely lead to appreciation of the currency. Also when a nation have a crave for domestic goods and services, it will likely lead to appreciation of the currency, while a crave for foreign goods and services will likely lead to depreciation of its currency [2]. If the domestic inflation rate exceeds the global average rate, it will likely lead to its currency's depreciation. However, if the domestic inflation rate is less than the global average rate then the chances are that its currency will appreciate [1] [3].

The post Bretton Woods' exchange rate models assume that there are close relationship between exchange rate movement and other macroeconomic variables [4].

When the monetary authority allows the exchange rate to be fixed, other macroeconomic variables are volatile. However, when exchange rate is allowed to float, it is known that the exchange rate becomes highly volatile in comparison with other macroeconomic variables [4] [5] [6].

\subsection{Economic Growth}

"Economic growth is the increase in the inflation-adjusted market value of the goods and services produced by an economy over time. It is conventionally measured as the percent rate of increase in real gross domestic product, or real GDP, usually in per capita terms. [7]. We can easily compute the economic growth rate using the time series data of the gross domestic product and the population for a given period.

Economic growth is measured by the increase in the amount of goods and services produced in a country. Growth is said to occur in a situation where a country's productive capacity is on the increase. This is then applied to produce more goods and services [8].

The Nigerian government has employed various strategies such as the use of monetary and fiscal policy, encourage export of goods and services, encourage the use of home made goods, structural adjustment program, etc. All these were aimed at achieving the following; price stabilization, job creation, maintaining balance of payment, and growing the economy [9].

In this paper we seek to establish the type of relationship that exists between exchange rate economic growth and other macroeconomic variables in Nigeria using the Vector Autoregressive (VAR) model.

\subsection{Exchange Rate and Economic Growth}

We recall that economic growth refer to the increase in the quantity of goods and services produced in a country as against those imported into the country. Thus economic growth has to do with productivity within a country. The question then arises. What is the relationship between exchange rate and economic growth. A strong exchange rate (the home currency appreciating over foreign 
currency) will lead to export being expensive. The demand for the country's goods and services by other countries will decrease leading to decrease in the quantity of goods and services produced in the country. This will result in negative economic growth (depressed economy). If the exchange rate is weak (the foreign currency appreciating over home currency), it will make exported goods and services cheaper at the international market, this will lead to increase in demand for the home country's goods and services. The increase in demand will stimulate the production of more goods and services in the home country. This will lead to a positive economic growth.

\section{Literature Review}

In an open world economy where goods are allowed to move freely across national boundaries without the restriction of tax or tariff, the exchange rate of a country is "determined by efficient labor and capital in producing tradable goods, as compared with producing non-tradable goods" [10]. Many research findings show that when exchange rate is highly volatile, then the volumes of goods traded will go down. "This is because in most international transactions, goods are delivered after a time gap and the contracts are denominated in terms of the currency of either the exporting or the importing country, and any unanticipated variation in exchange rates adversely affects the trade volume through their effects on income" [11].

When there is a rise in foreign demand for domestic currency it will lead to the strengthening of the domestic currency, when there is a fall in foreign demand for the domestic currency, it will lead to the weakening of the domestic currency. A rise in supply of the domestic currency will lead to the weakening of the domestic currency while a fall in the supply of the domestic currency will lead to the strengthening of the domestic currency [12].

Many researchers are of the opinion that exchange rate is critical to the performance of any economy. They hold that it is a major determinant of economic performance [13].

A cursory look at the performance of Nigeria's exchange rate between 1970-2010 suggests a Granger causality between exchange rate and other macroeconomic variables [14]. Some of the work done in this area include [15] who compared exchange rate with Consumer Price Index (CPI) and observed that import and the CPI are more positively correlated the ratio of the black market and the official rate. In [14], Akpan looked at the effects of the movement of the exchange rate on economic growth using the method of the ordinary least square (OLS) and asserted that exchange rate and economic growth are positively related. [14] in their study stated that it was monetary variables rather than exchange rate that affects economic growth. Finally [13] observed that exchange rate volatility contributed positively to GDP.

\section{Methodology}

The vector autoregressive (VAR) method is a simple and flexible tool used in 
modelling multivariate data. It has enjoyed wide usage both by researchers and practitioners in financial econometric. Its beauty is in the ability of the model to capture the dynamics of the variable of a time series data as well as its ability to forecast.

We can represent a $\operatorname{VAR}(p)$ model as

$$
v_{t}=c+X_{1} v_{t-1}+X_{2} v_{t-2}+X_{3} v_{t-3}+\cdots+X_{p} v_{t-p}+\varepsilon_{t}
$$

Such that $p$ is the lag order and $v_{t}=\left(v_{1 t}, \cdots, v_{k t}\right)^{\prime}$ is a $(k \times 1)$ random terms, the $X_{i}$ is the coefficient matrix, $c=\left(c_{1}, \cdots, c_{k}\right)^{\prime}$ is a $(k \times 1)$ constant term where $E\left(v_{t}\right)$ can be non zero. $\varepsilon_{t}$ is a vector of white noise with $E\left(\varepsilon_{t}\right)=0, E\left(\varepsilon_{t}, \varepsilon_{t}^{\prime}\right)=\xi_{\varepsilon}$ satisfy the non singularity condition.

Equation (1) can be represented as a VAR process of order 1

$$
V_{t}=C+X V_{t-1}+\epsilon_{t}
$$

where

$$
V_{t}=\left[\begin{array}{c}
v_{t} \\
v y_{t-1} \\
\vdots \\
v_{t-p+1}
\end{array}\right], \quad C=\left[\begin{array}{c}
c \\
0 \\
\vdots \\
0
\end{array}\right], \quad X=\left[\begin{array}{ccccc}
X_{1} & X_{2} & \ldots & X_{p-1} & X_{p} \\
I & 0 & \ldots & 0 & 0 \\
0 & I & \ldots & 0 & 0 \\
\vdots & \vdots & \ddots & \vdots & \vdots \\
0 & 0 & \ldots & I & 0
\end{array}\right], \epsilon_{t}=\left[\begin{array}{c}
\varepsilon_{t} \\
0 \\
\vdots \\
0
\end{array}\right]
$$

We can easily estimate Equation (2) separately using the method of OLS.

Proposition: The $\operatorname{VAR}(p)$ is said to be stable if the roots of $\operatorname{det}\left(I_{k}-X_{1} Z-\cdots-X_{p} z^{p}\right)=0$ lie outside the unit root circle. We can also say $V_{t}$ is stable if all the eigenvalues of the Companion matrix $X$ have modulus less than 1 .

The concept of stability is important because it guarantees the convergence of the process $V_{t}$.

\subsection{Selecting the Lag Length}

The lag length $p$ is selected in such a way as to minimize the information criteria (The commonly used criteria are: Akaike information criterion (AIC), Hannan-Quinn information criterion (HQ), Schwarz Information criterion (SC) and penalize large values of the selection criteria.

For a $\operatorname{VAR}(p)$ process, the information criteria is (IC) given by

$$
\operatorname{IC}(p)=\operatorname{In}|\bar{\xi}(p)|+g_{T} \cdot \varphi(k, p)
$$

where

$\bar{\xi}(p)=T^{-1} \sum_{t=1}^{T} \hat{\varepsilon}_{1} \hat{\varepsilon}_{T}^{\prime}$ is the residual covariance matrix without a degree of freedom correction from a $\operatorname{VAR}(p)$ model.

$g_{T}$ is a sequence indexed by the sample size $T$ and

$\varphi(k, p)$ is a penalty function which penalizes large $\operatorname{VAR}(p)$ models.

$$
H Q(p)=\operatorname{In}|\bar{\xi}(p)|+\frac{2 \ln T}{T} p k^{2}
$$




$$
\begin{gathered}
A I C(p)=\operatorname{In}|\bar{\xi}(p)|+\frac{2}{T} p k^{2} \\
S C(p)=\operatorname{In}|\bar{\xi}(p)|+\frac{\ln T}{T} p k^{2}
\end{gathered}
$$

\subsection{Granger Causality}

We say that $y_{t}$ does not Granger-cause $x_{t}$ if

$$
E\left[x_{t}-E\left(x_{t} \mid x_{t-1}, y_{t-1}, x_{t-2}, y_{t-2}, \cdots\right)\right]^{2}=E\left[x_{t}-E\left(x_{t} \mid x_{t-1}, x_{t-2}, \cdots\right)\right]^{2}
$$

If $y_{t}$ Granger-causes $x_{t}$ then one can predict $x_{t}$ better using the whole past of the $x_{t}$ and $y_{t}$ processes than using only the past of $x_{t}$. According to Granger, "a cause cannot come after the effect". Thus if a variable $x_{t}$ affect a variable $y_{t}$, then $x_{t}$ should help improving the prediction of $y_{t}$.

Let $v_{t}$ be a VAR process such that its moving Average (MA) representation in canonical form is

$$
V_{t}=\mu=\sum_{i=0}^{\infty} \phi_{i} \varepsilon_{t-i}=\mu+\phi(L) \varepsilon_{t}, \phi_{0}=I_{k}
$$

where

$\varepsilon_{t}$ is a white noise process with non-singular covariance matrix $\Sigma_{\varepsilon}$. Assume that $v_{t}$ consist of M-dimensional process $z_{t}$ and the $(k-M)$-dimensional process $x_{t}$ and the MA representation is partitioned accordingly,

$$
v_{t}=\left[\begin{array}{l}
z_{t} \\
x_{t}
\end{array}\right]=\left[\begin{array}{l}
\mu_{1} \\
\mu_{2}
\end{array}\right]+\left[\begin{array}{ll}
\phi_{11}(L) & \phi_{12}(L) \\
\phi_{21}(L) & \phi_{22}(L)
\end{array}\right]\left[\begin{array}{l}
\varepsilon_{1} \\
\varepsilon_{2}
\end{array}\right]
$$

A necessary and sufficient condition for $x_{t}$ being not Granger-caused for $z_{t}$, that is $z_{t}$ is not Granger-caused by $x_{t}$ is

$$
z_{t}\left(1 \mid\left\{x_{s} \mid s \leq t\right\}\right)=z_{t}\left(1 \mid\left\{z_{s} \mid s \leq t\right\}\right) \leftrightarrow \phi_{12, t}=0
$$

\subsection{Impulse Response}

An impulse response function traces the effect of a one-time shock to one of the innovations on current and future values of the endogenous variables (LLC, 2009).

Recall the Wold representation,

$$
y_{t}=\mu+\varepsilon_{t}+\eta_{1} \varepsilon_{t-1}+\eta_{2} \varepsilon_{t-2}+\cdots
$$

where

$$
\eta_{i j}^{s}=\frac{\partial y_{i, t+1}}{\partial \varepsilon_{j, t}}=\frac{\partial y_{i, t}}{\partial \varepsilon_{j, t-s}}, i, j=1, \cdots, T
$$

is the response of $y$ in period $t+s$ to shock in period $s$.

$\eta_{s}$ is the Impulse Response Function of $s$.

The $k \times k$ moving average matrices $\eta_{s}$ are determined recursively using

$$
\eta_{1}=\sum_{j=1}^{p-1} \eta_{s-j} A_{j}, \quad s=1,2, \ldots \cdots
$$




\section{Model Specification}

Exchange rate serves as our dependent variable. As s result of the heterogeneity of the variables' sizes, we take the natural log of some of the variables in other to homogenize the variables as well as make the model more robust.

We specify our Vector Autoregressive model as

$$
Y_{t}=C+\sum_{i=1}^{p} A_{i} Y_{t-1}+\epsilon_{t}
$$

where

$Y_{t}$ is a $(6 \times 1)$ random vector of endogenous variables being considered as exchange rate, Gross Domestic Product, government expenditure, inflation rate, external reserve, and oil revenue, the $A_{i}$ are fixed coefficient matrix, $C$ is a fixed $(6 \times 1)$ vector of intercept terms. $\varepsilon_{t}$ is a 6 -dimensional white noise and $p$ is the lag order.

The structural unrestricted VAR model for this study is specified as

$$
\begin{aligned}
& N A I R A_{t}=C_{i}+\sum_{i=1}^{p} X_{1 i} N A I R A_{t-1}+\sum_{i=1}^{p} X_{2 i} L G D P_{t-1}+\sum_{i=1}^{p} X_{3 i} L_{I N F_{t-1}} \\
& +\sum_{i=1}^{p} X_{4 i} \text { LEXRES }_{t-1}+\sum_{i=1}^{p} X_{5 i} L_{\text {GEXP }}+\sum_{i=1}^{p} X_{6 i} L O I L R E V+\epsilon_{i t} \\
& W_{t}=C_{i}+\sum_{i=1}^{p} X_{u i} N A I R A_{t-1}+\sum_{i=1}^{p} X_{v i} L G D P_{t-1}+\sum_{i=1}^{p} X_{w i} L I N F_{t-1} \\
& +\sum_{i=1}^{p} X_{x i} \text { LEXRES }_{t-1}+\sum_{i=1}^{p} X_{y i} L_{G E X P_{t-1}}+\sum_{i=1}^{p} X_{z i} L O I L R E V+\epsilon_{i t}
\end{aligned}
$$

where $W_{t}$ is a vector $(5 \times 1)$ matrix of other exogenous variables excluding NAIRA

$$
W_{t}=\left[\begin{array}{c}
L G D P_{t} \\
I N F_{t} \\
L E X R E S_{t} \\
L G E X P_{t} \\
L O I L R E V_{t}
\end{array}\right]
$$

where:

$N A I R A$ is the USD/NGN exchange rate

$I N F$ is the rate of Inflation

$L E X R E S$ is the natural log of external reserve.

$L G E X P$ is the natural log of Government expenditure

LOILREV is the natural log of oil revenue.

\section{Data, Result and Discussion}

\subsection{Data}

All data used in this work were obtained from Central Bank of Nigeria (CBN) website http://www.cenbank.org. The exchange rate represented by NAIRA is the cost of a Nigerian Naira in terms of the US dollars. The LGDP is used as a proxy for the economy. Other variables are as listed in 4.0. As a result of the heterogeneous nature of the data, we took the natural log of the variables except inflation and foreign exchange, this is to homogenize the variables. We did not use the natural logarithm of inflation and foreign exchange because their series are 
homogenous and need no further transformation. The model was analysed using Eview 7.0 Enterprise Edition.

\subsection{Result}

The lag exclusion criteria as well as the lag inclusion criteria (Table 1 and Table 2) favours the use of an optimal lag of 1, therefore our model is a VAR(1) model. The eigenvalues are estimated to be $0.974712,0.97471,0.485356,0.485356$, 0.3902 , and 0.291131 . This implies that all the eigenvalues lie within the unit circle (see Figure 1), hence our VAR model is stable. The Johansen cointegration test showed that there are at most 2 cointegrating equations with eigenvalues greater than 0.5 indicating a long-run relationship among the variables. The Granger causality test (see Table 3), reveals that causality among the variables are unidirectional. NAIRA was found to Granger cause LGDP, LOIREV and LGEXP. On the other hand LGDP Granger causes LGEXP while LEXRES Granger causes LGEXP.

The impulse response (see Figure 2), shows that a positive on NAIRA has no immediate impact on the variables but later elicits a negative impact on LOILREV and a weak positive impact on the other variables. A shock on LGDP has the greatest negative impact on NAIRA. It is interesting to note the shock persistence of NAIRA.

The variance decomposition (see Figure 3), indicates that NAIRA is mostly explained by itself while LGDP is explained by itself while LGDP is explained by itself initially and later mostly by NAIRA.

\section{Summary and Conclusions}

We can summarize our findings as follows: The exchange rate seems to influence the economy as shown by Granger causality, though a shock on NAIRA has a weak impact on the economy; The variance decomposition (see Figure 3), shows that exchange rate plays a critical role in explaining changes in the economy. It is surprising however to realize that neither LGDP nor any of the other variables Granger causes NAIRA. Also a positive shock on the economy sends the NAIRA on a downward slide.

In conclusion, we are of the opinion that diversifying the economy will exploit the weakness of NAIRA and give us a competitive edge in the international market.

\section{Acknowledgements}

We acknowledge the contributions of the anonymous referee.

\section{References}

[1] Islam, M.R. and Sardar, N.M. (2007) Quantitative Exchange Rate Economics in Developing Countries. Palgrave Macmillam, New York.

[2] Arize, C. and Osang, T. (2000) Exchange Rate Volatility and Foreign Trade: Evidence from Thirteen LDCs. Journal of Business and Economic Statistics, 18, 10-17. 
[3] Giovannini, A. (1988) Exchange Rates and Traded Goods Prices. Journal of International Economics, 24, 45-68. https://doi.org/10.1016/0022-1996(88)90021-9

[4] MacDonald, R. (2008) Three Exchange Rate Puzzles: Fact or Fiction? In: Pavlos Karadeloglou, V.T., Ed., Exchange Rates and Macroeconomic Dynamics, Palgrave, New York. https://doi.org/10.1057/9780230582699_2

[5] Baxter, M. and Stockman, A. (1989) Business Cycles and the Exchange-Rate System. Journal of Monetary Economics, 23, 377-400. https://doi.org/10.1016/0304-3932(89)90039-1

[6] Flood, R.P. and Rose, A.K. (1999) Understanding Exchange Rate Volatility without the Contrivance of Macroeconomics. Economic Journal, 109, F660-F672. https://doi.org/10.1111/1468-0297.00478

[7] IMF (October 2012) Statistics on the Growth of the Global Gross Domestic Product (GDP) from 2003 to 2013.

[8] Akpan, P.L. (2008) Foreign Exchange Market and Economic Growth in an Emerging Petroleum Based Economy: Evidence from Nigeria (1970-2003). African Economic and Business Review, 6, 46-58.

[9] Ismaila, M. and Imoughele, L.E. (2015) Macroeconomic Determinants of Economic Growth in Nigeria: A Co-integration Approach. International Journal of Academic Research in Economics and Management Sciences, 4, 34-46.

[10] Batra, R.N. and Ramachandran, R. (1980) Multinational Firms and the Theory of International Trade and Investment. The American Economic Review, 70, 278-290.

[11] Asseery, A. and Peel, D.A. (1991) The Effects of Exchange Rate Volatility on Exports. Economics Letters, 37, 173-177.

https://doi.org/10.1016/0165-1765(91)90127-7

[12] Barro, R.J. and Gordon, D. 1983) A Positive Theory of Monetary Policy in a Natural Rate Model. Journal of Political Economy, 91, 589-610. https://doi.org/10.1086/261167

[13] Azeez, B.A., Kolapo Funso, T. and Ajayi, L.B. (2012) Effect of Exchange Rate Volatility on Macroeconomic Performance in Nigeria. Interdisciplinary Journal of Contemporary Research in Business, 4, 149-155.

[14] Akpan, E.O. and Atan, J.A. (2010) Effects of Exchange Rate Movements On Economic Growth in Nigeria. CBN Journal of Applied Statistics, 2, 1-14.

[15] Adekunle, K. (2010) Exchange Rates and the Consumer Price Index in Nigeria: A Causality Approach. Journal of Emerging Trends in Economics and Management Sciences, 1, 114-120. 


\section{Appendix}

Table 1. The lag exclusion criteria.

VAR Lag Exclusion Wald Tests

Date: 08/27/15 Time: 00:04

Sample: 19702010

Included observations: 37

Chi-squared test statistics for lag exclusion:

Numbers in [ ] are p-values

\begin{tabular}{cccccccc}
\hline & NAIRA & LGDP & INF & LEXRES & LGEXP & LOILREV & Joint \\
\hline Lag 1 & 48.38718 & 23.97403 & 15.47317 & 7.068986 & 2.098368 & 3.388332 & 119.3899 \\
& {$[9.89 \mathrm{e}-09]$} & {$[0.000528]$} & {$[0.016879]$} & {$[0.314515]$} & {$[0.910433]$} & {$[0.758762]$} & {$[7.19 \mathrm{e}-11]$} \\
Lag 2 & 10.09263 & 2.086675 & 3.753658 & 4.271518 & 3.179333 & 2.889974 & 36.98711 \\
& {$[0.120805]$} & {$[0.911557]$} & {$[0.709972]$} & {$[0.639985]$} & {$[0.786025]$} & {$[0.822524]$} & {$[0.423175]$} \\
Lag 3 & 16.53311 & 4.902342 & 12.98908 & 4.380938 & 1.540970 & 2.444118 & 77.76293 \\
& {$[0.011161]$} & {$[0.556398]$} & {$[0.043210]$} & {$[0.625270]$} & {$[0.956727]$} & {$[0.874669]$} & {$[6.68 \mathrm{e}-05]$} \\
Lag 4 & 6.202100 & 12.11665 & 5.958065 & 5.457151 & 2.469807 & 3.829662 & 54.89209 \\
& {$[0.400936]$} & {$[0.059416]$} & {$[0.427904]$} & {$[0.486651]$} & {$[0.871831]$} & {$[0.699715]$} & {$[0.022714]$} \\
Df & 6 & 6 & 6 & 6 & 6 & 6 & 36 \\
\hline
\end{tabular}

Table 2. The lag inclusion criteria.

VAR Lag Order Selection Criteria

Endogenous variables: NAIRA LGDP INF LEXRES LGEXP LOILREV

Exogenous variables: $\mathrm{C}$

Date: 08/27/15 Time: 00:05

Sample: 19702010

Included observations: 37

\begin{tabular}{ccccccc}
\hline Lag & LogL & LR & FPE & AIC & SC & HQ \\
\hline 0 & -305.6071 & NA & 0.832305 & 16.84363 & 17.10486 & 16.93572 \\
1 & -130.2836 & $284.3084^{*}$ & $0.000459^{*}$ & 9.312628 & $11.14124^{\star}$ & $9.957298^{\star}$ \\
2 & -99.94526 & 39.35786 & 0.000731 & 9.618663 & 13.01465 & 10.81591 \\
3 & -48.51716 & 50.03815 & 0.000503 & 8.784712 & 13.74808 & 10.53453 \\
4 & 4.982721 & 34.70263 & 0.000585 & $7.838772^{*}$ & 14.36952 & 10.14117 \\
\hline
\end{tabular}

*indicates lag order selected by the criterion; LR: sequential modified LR test statistic (each test at $5 \%$ level); FPE: Final prediction error; AIC: Akaike information criterion; SC: Schwarz information criterion; HQ: Hannan-Quinn information criterion. 
Table 3. The Granger causality test.

Pairwise Granger Causality Tests

Date: 08/28/15 Time: 14:13

Sample: 19702010

Lags: 1

Null Hypothesis:
LEXRES does not Granger Cause INF

INF does not Granger Cause LEXRES

LGDP does not Granger Cause INF

INF does not Granger Cause LGDP

LGEXP does not Granger Cause INF

INF does not Granger Cause LGEXP

LOILREV does not Granger Cause INF

INF does not Granger Cause LOILREV

NAIRA does not Granger Cause INF

INF does not Granger Cause NAIRA

LGDP does not Granger Cause LEXRES

LEXRES does not Granger Cause LGDP

LGEXP does not Granger Cause LEXRES

LEXRES does not Granger Cause LGEXP

LOILREV does not Granger Cause LEXRES

LEXRES does not Granger Cause LOILREV

NAIRA does not Granger Cause LEXRES

LEXRES does not Granger Cause NAIRA

LGEXP does not Granger Cause LGDP

LGDP does not Granger Cause LGEXP

LOILREV does not Granger Cause LGDP

LGDP does not Granger Cause LOILREV

NAIRA does not Granger Cause LGDP

LGDP does not Granger Cause NAIRA

LOILREV does not Granger Cause LGEXP

LGEXP does not Granger Cause LOILREV

NAIRA does not Granger Cause LGEXP

LGEXP does not Granger Cause NAIRA

NAIRA does not Granger Cause LOILREV

LOILREV does not Granger Cause NAIRA 
Roots of Characteristic Polynomial

Endogenous variables: NAIRA LGDP INF LEXRES LGEXP LOILREV

Exogenous variables: $\mathrm{C}$

Lag specification: 11

Date: 08/29/15 Time: 01:27

\begin{tabular}{ll}
\hline \hline \multicolumn{1}{c}{ Root } & Modulus \\
\hline \hline $0.974113-0.034166 i$ & 0.974712 \\
$0.974113+0.034166 i$ & 0.974712 \\
$0.471131-0.116643 i$ & 0.485356 \\
$0.471131+0.116643 i$ & 0.485356 \\
0.390200 & 0.390200 \\
0.291131 & 0.291131 \\
\hline \hline
\end{tabular}

No root lies outside the unit circle.

VAR satisfies the stability condition.
Inverse Roots 01 /R Characteristic Polynomia

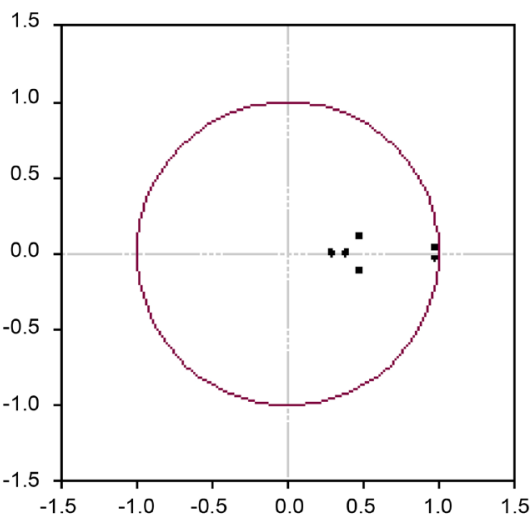

Figure 1. Roots of Characteristics Polynomial.
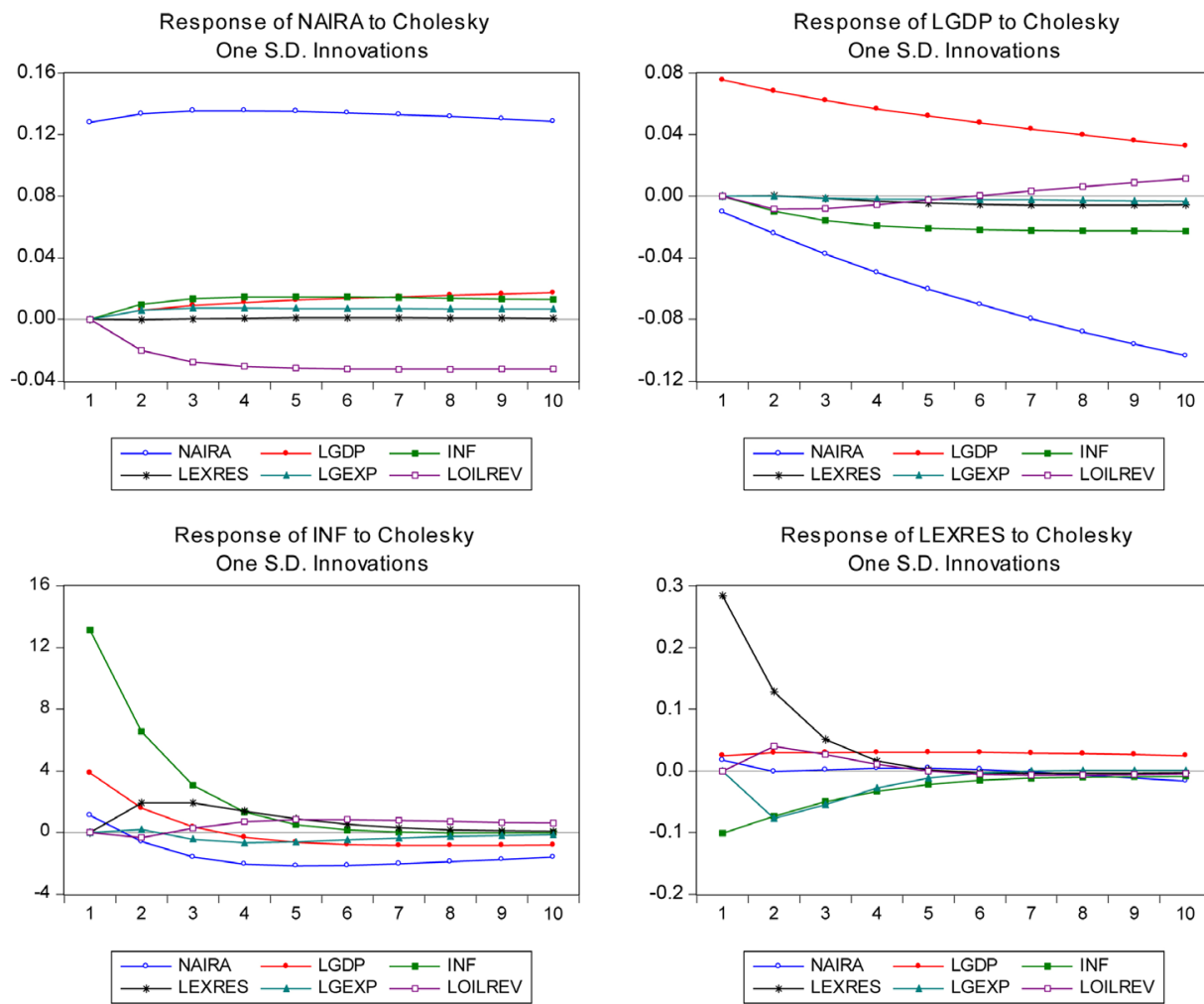

Response of LEXRES to Cholesky

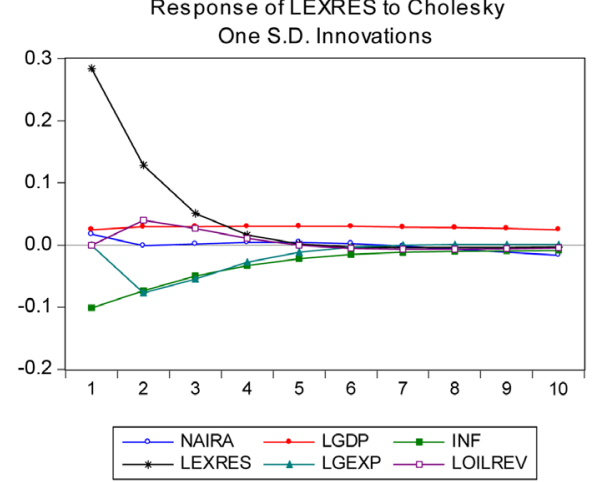

Response of LGEXP to Cholesky One S.D. Innovations

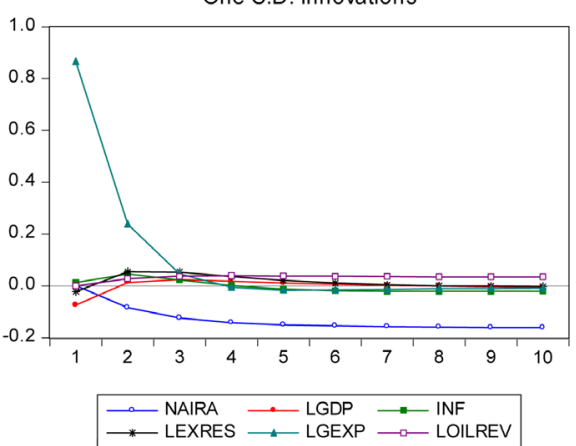

Response of LOILREV to Cholesky One S.D. Innovations

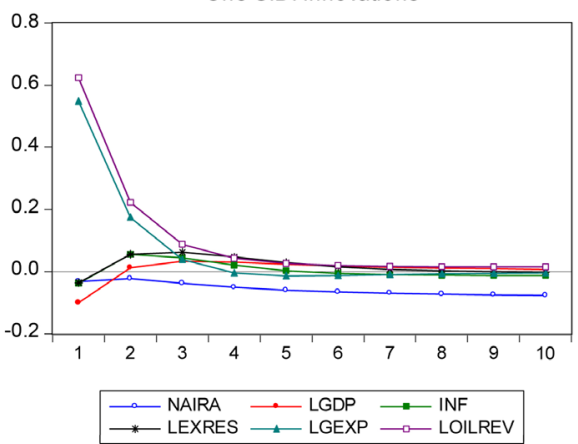

Figure 2. Impulse response. 

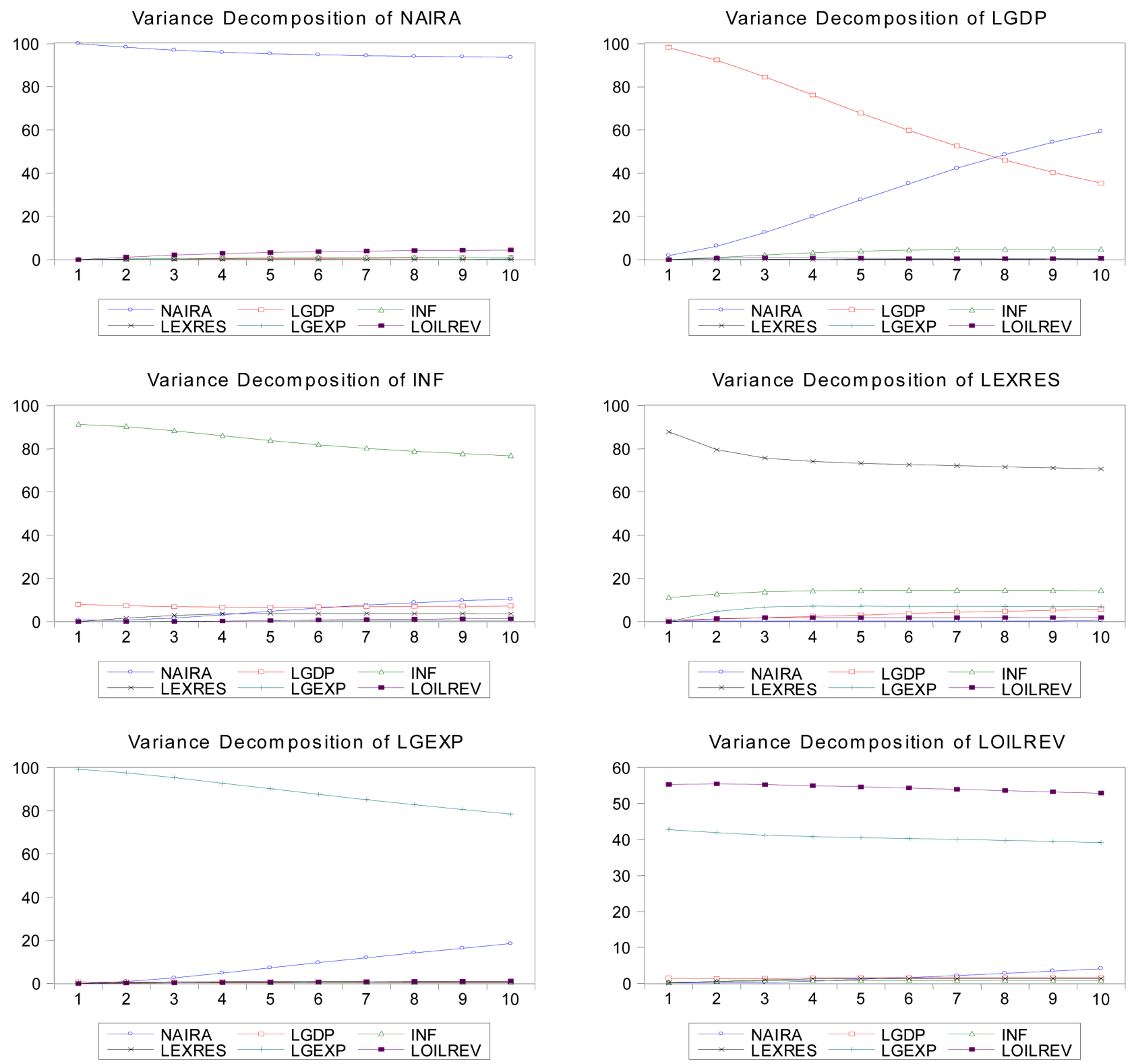

Figure 3. Variance decomposition. 